\title{
Alterações histológicas em placas ósseas do peixe cascudo Rineloricaria strigilata (Hensel) (Teleostei, Loricariidae) e sua freqüência no lago Guaíba, Rio Grande do Sul, Brasil
}

\author{
Fábio Flores-Lopes ${ }^{1}$ \\ Luiz R. Malabarba ${ }^{1,2}$ \\ Edson H.L. Pereira ${ }^{2}$ \\ José F. Pezzi da Silva ${ }^{2}$
}

\begin{abstract}
Description of histological abnormalities in the bony plates of the loricariid catfish Rineloricaria strigilata (Hensel) (Teleostei, Loricariidae) and analysis of its frequency in the lake Guaiba, Rio Grande do Sul, Brazil. Little information is available about natural populations of fishes exposed to polluted waters in Brazil. Contaminants may be lethal or predispose fishes to sickness, being the analysis of aquatic organisms a good indicator of environmental quality. The violinha, Rineloricaria strigilata (Hensel, 1868), is a common loricariid catfish in the Guaiba lake basin, Rio Grande do Sul, Brazil, and has been selected as a bioindicator for being resident, occurring in more than $50 \%$ of the samples, and by showing externally detectable neoplasies. These are characterized by its dark pigmentation, bony plates hypertrophy, and hypertrophy and irregular arrangement of the odontodes. Histology showed hypertrophied epitelial tissues, with an increased number of secretory cells, blood cells, and melanina pigments, giving the dark appearance to the neoplasm. Observed frequencies of neoplasm were higher in lake Guaiba than in comparative samples. Inside lake Guaiba, a pattern of distribution of neoplasm was observed, with the absence of neoplasm in fishes at the collected site that receives water from rio Jacuí, and frequencies of 3.04 to $16.81 \%$ in the collection localities in front of Porto Alegre and downstream localities, that receive water from rio Jacui, rio dos Sinos and rio Gravataí, that drain urban and industrial area of Porto Alegre and neighborhood cities.

KEY WORDS. Rineloricaria strigilata, bioindicator, neoplasm
\end{abstract}

Peixes são organismos freqüentemente expostos a águas contaminadas, especialmente em áreas onde a taxa de diluição de resíduos é baixa (BERNET et al. 1999). Segundo SNIESZKO (1974), há extensa literatura sobre patologias de peixes causadas por vários poluentes, mas poucas informações estão disponiveis sobre os efeitos de substâncias tóxicas no ambiente. Em países como o Brasil, onde estudos ambientais são ainda incipientes, as informações disponíveis sobre efeitos de poluentes em espécies de peixes são ainda mais escassos.

1) Pós-Graduação em Biologia Animal, Departamento de Zoologia, Instituto de Biociências, Universidade Federal do Rio Grande do Sul. Avenida Bento Gonçalves 9500, prédio 43435. bloco IV, 90540-000 Porto Alegre, Rio Grande do Sul, Brasil.

2) Museu de Ciências e Tecnologia, Pontifícia Universidade Católica do Rio Grande do Sul. Avenida Ipiranga 6681, Caixa Postal 1429, 90619-900 Porto Alegre, Rio Grande do Sul, Brasil. 
Além do monitoramento químico tradicional feito através da análise da concentração de algumas substâncias, que não podem estar presentes acima de determinadas concentrações, a análise direta da saúde dos organismos aquáticos representa um indicador importante da qualidade da água em recursos hídricos naturais (GONZALEZ et al. 1993). Mudanças na química da água podem ser letais para peixes ou estressá-los suficientemente predispondo-os uma doença (WALTERS \& PLUMB 1980), sendo estas o resultado final de uma interação entre um estímulo nocivo e um sistema biológico (SNIESZKo 1974).

A observação direta da saúde dos organismos aquáticos permite a detecção de efeitos nocivos sobre o ambiente e organismos aquáticos não detectados no monitoramento químico tradicional. As limitações, deste último, residem na falta de informações sobre toxicidade de alguns elementos ou compostos químicos, na falta de informações sobre efeitos sinérgicos, aditivos ou antagônicos ocasionados pela combinação das substâncias tóxicas existentes ou reações com o meio químico, ou no fato de existirem algumas centenas de substâncias potencialmente tóxicas cuja análise nem sempre é disponível ou economicamente viável (EPA 1984: 9017; Peltier \& Weber 1985: 1). Podemos adicionar a esta lista de limitações a dificuldade em estabelecer limites toleráveis de concentração de substâncias potencialmente tóxicas baseados no estudo de alguns poucos organismos, uma vez que diferentes espécies podem apresentar diferentes respostas à presença de um mesmo tipo de poluente (SPRAGUE 1985).

Entre os efeitos ou danos detectáveis causados por poluentes em peixes, passiveis de medição quantitativa e/ou qualitativa, incluem-se (1) mutações genéticas, (2) doenças, (3) mudanças no comportamento, (4) disfunções físicas (incluindo disfunções na reprodução), (5) deformações físicas ou displasias, (6) morte e (7) câncer ou neoplasias (BERGMAN 1985).

A possibilidade de uso de um destes parâmetros na avaliação da degradação ambiental é testada aqui com base na análise de populações naturais da violinha Rineloricaria strigilata (Hensel 1868) capturados ao longo de cinco anos (19921996) de amostragem no lago Guaíba, Rio Grande do Sul, Brasil. Neste estudo são descritas histologicamente e quantificadas as ocorrências de neoplasias em placas ósseas externamente visíveis deste peixe-cascudo, e avaliada criticamente a possibilidade de utilização deste parâmetro como indicador da qualidade da água na bacia amostrada.

\section{MATERIAL E MÉTODOS}

\section{Área de estudo}

O lago Guaíba, objeto deste estudo, compreende um dos mais importantes recursos hídricos do estado do Rio Grande do Sul, servindo ao abastecimento da grande Porto Alegre e algumas cidades circunvizinhas, abrangendo diretamente cerca de um milhão e 500 mil habitantes. A área abrangida pela bacia do lago Guaíba corresponde a $85.950 \mathrm{~km}^{2}$ ou $30 \%$ da área geográfica do estado do Rio Grande do Sul (FEPAM 1992) onde se concentram $70 \%$ da população gaúcha e cerca de $80 \%$ do PIB do estado (EMATER 1991). Devido a maior concentração urbana e industrial 
na área, o lago Guaíba recebe contribuições de poluentes, principalmente de despejos de efluentes industriais e domésticos, diretamente ou através de seus tributários, como os rios Gravataí, Sinos e Caí. O controle da poluição hídrica no lago Guaíba e a identificação de seus causadores torna-se uma tarefa complexa à medida que somam-se as fontes de possíveis poluentes. As áreas amostradas (Fig. 1) incluem dois pontos distintos de aporte de água no lago Guaíba, o Saco da Alemoa (I), que recebe a água oriunda do rio Jacuí somente, e a Ponta da Cadeia (II), por onde escoa a água procedente dos rios Jacuí, Gravataí e Sinos, sendo que os dois últimos drenam grande parte da região metropolitana de Porto Alegre. Além destes, foram amostrados quatro pontos na margem oeste do lago Guaíba, nas imediações da foz do arroio Celupa (III); na praia da Alegria (IV); na ponta da Figueira (V), em Guaíba, e em frente à cidade de Barra do Ribeiro (VI).

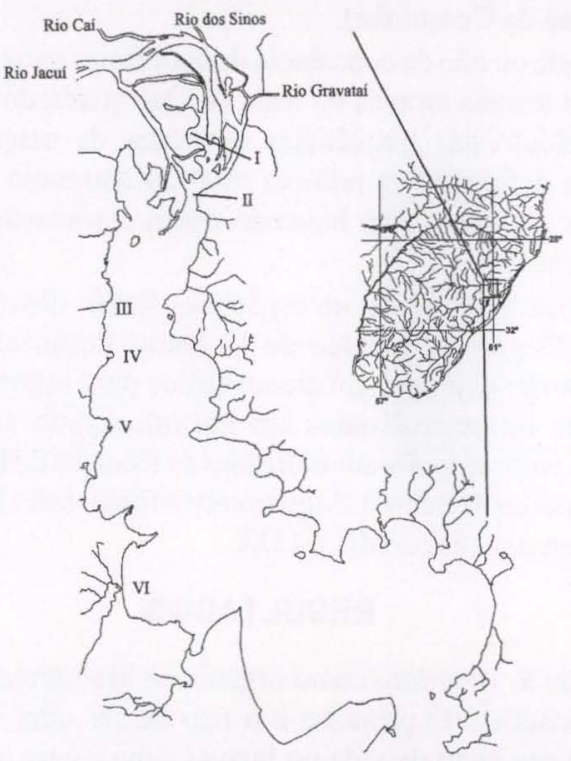

Fig. 1. Bacias hidrográficas do sul do Brasil e Uruguai e, em detalhe, o lago Guaíba e principais tributários com as localidades amostradas: Saco da Alemoa (I), Ponta da Cadeia (II), foz do arroio Celupa (III); Praia da Alegria (IV); Ponta da Figueira (V), e em frente à cidade de Barra do Ribeiro (VI).

\section{Metodologia}

A análise quantitativa da freqüência de neoplasias foi baseada em um total de 4928 exemplares de $R$. strigilata capturados ao longo de três períodos de um ano de amostragem, entre fevereiro e dezembro de 1992, entre maio de 1993 e março de 1994, e entre novembro de 1995 e outubro de 1996. A descrição histológica se baseia em 12 exemplares de um total de 428 espécimes com neoplasias em placas ósseas. Os exemplares foram coletados com redes de arrasto do tipo picaré (malha 
$5 \mathrm{~mm}, 12 \mathrm{~m}$ comprimento e $1,5 \mathrm{~m}$ altura) em profundidades inferiores a $1,2 \mathrm{~m}$, e redes de espera (malhas $15 \mathrm{~mm}$ e $25 \mathrm{~mm}, 20 \mathrm{~m}$ comprimento cada e 1,6 m altura) em profundidades de $1,5 \mathrm{a} 2 \mathrm{~m}$, e fixados em formol a $10 \%$ em campo para posterior análise morfológica e histológica em laboratório. Como amostras comparativas, foram examinados 145 exemplares de $R$. strigilata de diversas localidades do Rio Grande do Sul, depositados na coleção de peixes do Museu de Ciências e Tecnologia da PUCRS, da bacia do rio Jacuí (MCP 9487, 1 ex., rio Pardinho; MCP 9787, 2 ex., arroio Sampaio; MCP 11219, 2 ex., rio Caí; MCP 16616, 4 ex., arroio Santa Bárbara; MCP 17265, 18 ex., rio São Sepé; MCP 18394, 2 ex., rio dos Sinos; MCP 18649, 6 ex., arroio Andreas; 14 ex. não catalogados rio Pardinho), bacia da laguna dos Patos (MCP 9158, 2 ex., laguna dos Patos; MCP 15378, 40 ex., arroio Velhaco; MCP 11335, 7 ex., arroio dos Ladrões), bacia da lagoa Mirim (MCP 11581, 10 ex., lagoa Mirim; MCP 14987, 25 ex., rio Jaguarão) e sistema do rio Tramandaí (MCP 15337, 12 ex., lagoa da Cerquinha).

A casualidade ou não de ocorrência de neoplasias entre os pontos amostrados do lago Guaíba foi testada através do teste do Qui-quadrado simples. O postulado que permitiu o cálculo das frequêencias esperadas de neoplasias em cada local amostrado foi que a freqüência relativa total da anomalia para cada espécie se repetiria em todos os locais, não havendo assim associação entre os locais e as freqüências observadas.

Para a análise histológica, os espécimes foram descalcificados com ácido tricloroacético a $5 \%$ por um período de 12 horas. Posteriormente foi utilizada a técnica de rotina de desidratação em álcool etílico para impregnação e inclusão em parafina. Os cortes foram realizados em um micrótomo com espessura de sete micrômetros. Para coloração, foram utilizadas as técnicas de Hematoxilina e Eosina e APS (Ácido Periódico de Schiff). Alguns cortes foram selecionados e fotografados com um fotomicroscópio Zeiss MC 80 DX.

\section{RESULTADOS}

A escolha de R. strigilata como organismo bioindicador no lago Guaíba foi baseada em três critérios. O primeiro é o fato de ser uma espécie residente, que desenvolve todo o seu ciclo de vida no lago Guaíba e para a qual se desconhece a existência de migração trófica ou reprodutiva. O segundo critério foi a constância de ocorrência nas amostragens. Rineloricaria strigilata foi uma espécie constante, ocorrendo em $71,43 \%, 80,95 \%$ e $91,67 \%$ das amostras em cada um dos três períodos de amostragens tomadas no lago Guaiba (1992, 1993-1994, 1995-1996, respectivamente). O terceiro critério empregado na sua escolha foi a presença de neoplasias externamente detectáveis nos tecidos analisados, descritos a seguir.

\section{Alterações macroscópicas}

Rineloricaria strigilata é um peixe-cascudo da família Loricariidae, e, como os demais, apresenta o corpo revestido por séries longitudinais de placas ósseas ao invés de escamas. As placas ósseas dos cascudos apresentam-se ainda recobertas por odontodes, ou pequenos dentículos ósseos, regularmente arranjados na sua superfície (Fig. 3B). 
Neoplasias em placas ósseas de $R$. strigilata são detectáveis macroscopicamente pela coloração escura do tecido afetado e por apresentarem-se hipertrofiadas e mais elevadas do que as placas ósseas adjacentes (Figs 2, 3D), bem como pela hipertrofia e arranjo irregular dos odontodes (Fig. 3A, C). Estes neoplasmas não ocorrem em regiões específicas do corpo do peixe, podendo ser observados na região dorsal ou ventral, da cabeça, abdome ou região caudal.

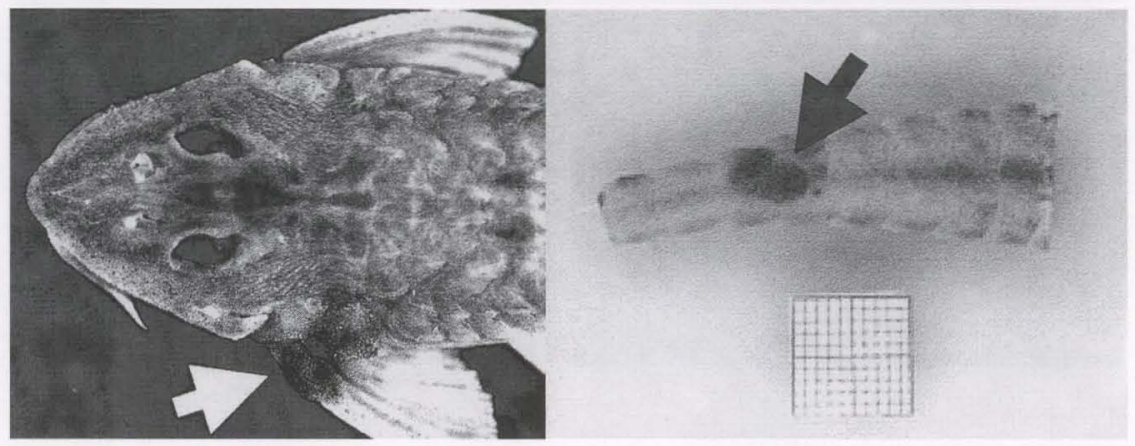

Fig. 2. Neoplasias observadas próximo a cabeça e no pedúnculo caudal de Rineloricaria strigilata.

\section{Análise histológica}

Espécimes normais de $R$. strigilata possuem uma epiderme formada por tecido epitelial estratificado, constituído por um número variável de camadas de células, geralmente oscilando de cinco a dez. Por entre as células epiteliais aparecem células circulares, grandes e com função secretora. Estas células, chamadas de goblet cells são responsáveis pela secreção de muco. Algumas dessas células secretoras se localizam logo acima das células do estrato germinativo do tecido epitelial. Entremeadas nas células do tecido epitelial ocorrem células sangüíneas de tamanho pequeno, geralmente linfócitos e leucócitos (Fig. 4).

Abaixo da epiderme, ligada à membrana basal ocorre uma fina camada de melanina junto com tecido conjuntivo frouxo. Em seguida do conjuntivo estão placas ósseas interligadas por tecido conjuntivo frouxo, e apoiadas sobre um tecido muscular estriado esquelético. Destas placas ósseas partem, externamente, os odontodes, estruturas também ósseas e de forma cônica. No interior de cada odontodeo há um canal que é preenchido por medula óssea. Os odontodes estão todos orientados na mesma direção e aparecem circundados externamente por tecido epitelial até uma certa altura de seu comprimento (Fig. 4A).

A análise histológica das neoplasias demonstrou uma alteração na configuração normal dos tecidos nos locais afetados. Nestes, observou-se uma hiperplasia do tecido epitelial, ou seja, ocorre um aumento no número de células e de camadas de células. Também houve um acentuado aumento no número de células secretoras e células sangüíneas inseridas no tecido epitelial (Fig. 4 B-D). As células secretoras que se localizam logo acima do estrato germinativo, mostraram-se maiores e com 

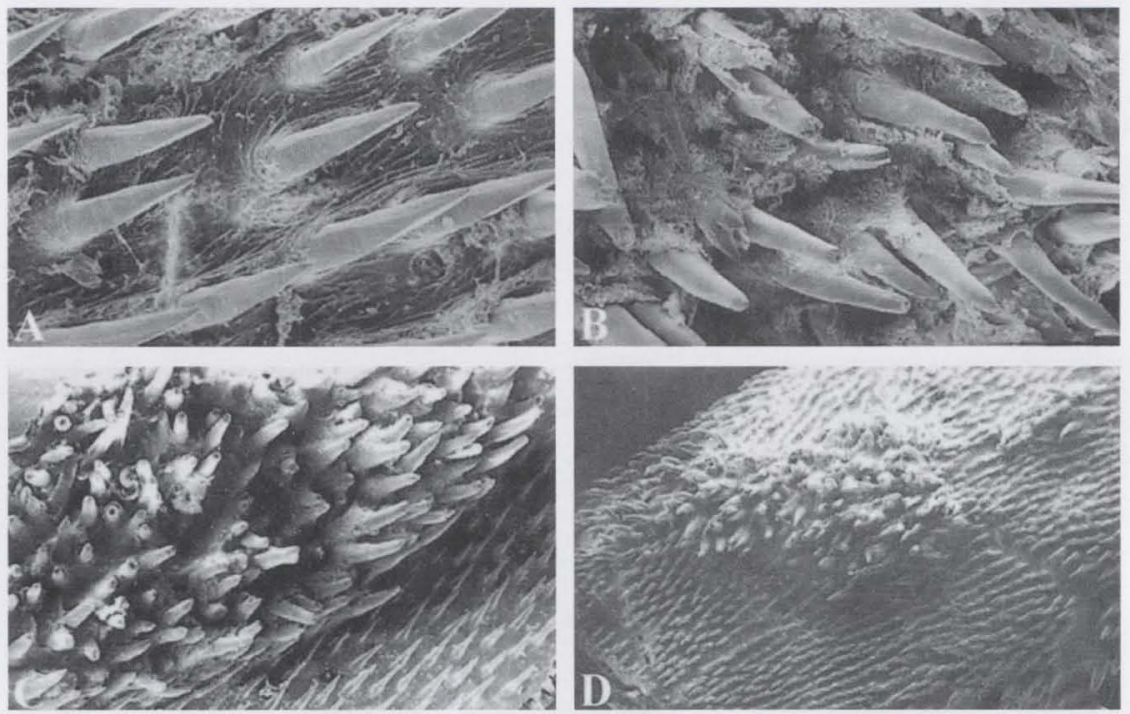

3
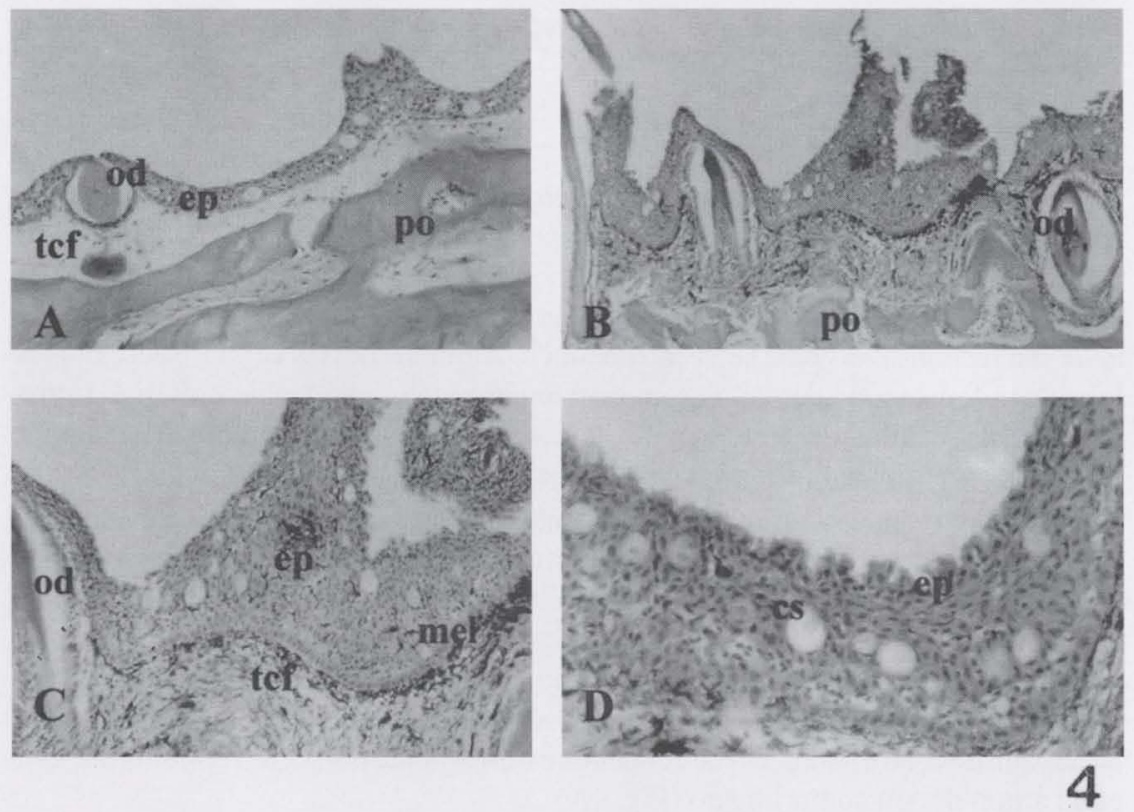

Figs 3-4. (3) Placas ósseas do cascudo Rineloricaria strigilata: (A) organização normal dos odontodes; (B) detalhe dos odontodes desordenados no tecido com neoplasia; (C) visualização de duas placas contiguas, uma com neoplasia (acima a esquerda) e outra normal (abaixo a direita); (D) placa ósseas com neoplasia. (4) Cortes histológicos em placas ósseas: (A-B) placas normais; (C-D) placas ósseas com neoplasias. (ep) Epiderme, (cs) células secretoras de muco, (mel) camada de melanina, (tcf) tecido conjuntivo frouxo, (po) placas ósseas, (me) tecido muscular estriado esquelético, (od) odontodes. 
várias células sangüíneas associadas. Por entre as células de tecido epitelial há a presença de pigmentos de melanina, o que dá uma cor escura ao neoplasma. Abaixo da epiderme existe uma grossa camada de tecido conjuntivo frouxo. Entremeada ao tecido conjuntivo, ocorre uma grande pigmentação de melanina, seguida das placas ósseas interligadas por tecido conjuntivo frouxo (Fig. 4B,C). No corte histológico das neoplasias, os odontodes aparecem em seções diferentes, por não estarem orientados todos no mesmo sentido. Eles ocorrem em tamanho aumentado, com uma medula interna composta de tecido conjuntivo e células sangüíneas.

\section{Freqüências observadas versus freqüências esperadas de neoplasias}

A comparação estatística das freqüências observadas nas amostras do lago Guaíba com as observadas em amostras comparativas de outras localidades (Tab. I) demonstrou a não casualidade das ocorrências de neoplasias em placas ósseas de $R$. strigilata em relação aos locais analisados, sendo as freqüências relativas observadas nas amostras do lago Guaíba, nos três períodos de amostragem $(8,31 \%, 7,34 \%$ e $9,02 \%)$, mais elevadas do que a freqüência observada na amostra comparativa $(2,76 \%)$.

Tabela I. Teste do Qui-Quadrado simples em Rineloricaria strigilata comparando os três períodos de amostragens no lago Guaiba com amostras controle. $G \mathrm{~L}=4, X^{2}$ tab. $=9,488$ para alfa $=0,05$; (fi) freqüência observada na amostra; ( $F i)$ freqüência esperada na amostra.

\begin{tabular}{lrrrrr}
\hline \multicolumn{1}{c}{ Amostra } & $\mathrm{N}$ & $\%$ & $\mathrm{fi}$ & $\mathrm{Fi}$ & $\boldsymbol{X}^{2}$ \\
\hline 1992 & 409 & 8,31 & 34 & 34,80 & 0,02 \\
$1993-1994$ & 817 & 7,34 & 60 & 69,60 & 1,31 \\
$1995-1996$ & 3702 & 9,02 & 334 & 315,00 & 1,12 \\
L. Pa. / 92 & 1 & 0,00 & 0 & 0,09 & 0,09 \\
Amostra comparativa & 145 & 2,76 & 4 & 12,30 & 5,64 \\
\hline Ttal & 5074 & & 432 & & 8,18 \\
\hline
\end{tabular}

A comparação estatística das frequiências observadas entre os pontos amostrados no lago Guaíba demonstrou a não casualidade das ocorrências de neoplasias em placas ósseas de $R$. strigilata em relação aos locais analisados no segundo (1993-1994) e terceiro (1995-1996) períodos de amostragem. Em ambos os períodos, a freqüência desta neoplasia foi igual a zero no ponto I (Tab. II), em contrapartida a elevadas freqüências observadas no ponto II e em todas as localidades a jusante (3,39-16,81\% em 1993-1994, e 3,04-15,51\% em 1995-1996). Embora não tenha sido demonstrada estatisticamente a não casualidade na ocorrência desta neoplasia entre os pontos amostrados no primeiro período de amostragem (1992), foi igualmente observada uma freqüência igual a zero no ponto I e freqüências elevadas no ponto II e localidades a jusante $(7,14-14,71 \%)$.

\section{DISCUSSÃO}

Neoplasmas ou neoplasias são definidas como um distúrbio do crescimento, caracterizados principalmente por uma incessante, anormal e excessiva proliferação de células. Os espécimes analisados de $R$. strigilata do lago Guaíba apresentaram estas neoplasias, visíveis macroscopicamente, nas placas ósseas e nos odontodes de revestimento do corpo. Estas neoplasias apresentavam um padrão bem definido, mostrando a mesma constituição em qualquer parte do corpo. 
Tabela II. Teste do Qui-Quadrado simples para a ocorrência de neoplasias em placas ósseas em Rineloricaria strigilata $\left(G L=5, X^{2}\right.$ tab. $=11,07$ para alfa $=0,05$; (fi) freqüencia observada na amostra; (Fi) freqüência esperada na amostra.

\begin{tabular}{|c|c|c|c|c|c|c|c|c|c|c|c|c|c|c|c|}
\hline \multirow{2}{*}{ Local } & \multicolumn{5}{|c|}{1992} & \multicolumn{5}{|c|}{$1993-1994$} & \multicolumn{5}{|c|}{$1995-1996$} \\
\hline & $\mathrm{N}$ & $\%$ & fi & $\mathrm{Fi}$ & $x^{2}$ & $\mathrm{~N}$ & $\%$ & fi & $\mathrm{Fi}$ & $x^{2}$ & $\mathrm{~N}$ & $\%$ & fi & $\mathrm{Fi}$ & $x^{2}$ \\
\hline 1 & 24 & 0,00 & 0 & 2,00 & 2,00 & 30 & 0,00 & 0 & 2,20 & 2,20 & 34 & 0,00 & 0 & 3,07 & 3,07 \\
\hline ॥ & 68 & 14,71 & 10 & 5,65 & 3,34 & 59 & 3,39 & 2 & 4,33 & 1,26 & 230 & 3,04 & 7 & 20,80 & 9,11 \\
\hline III & 44 & 9,09 & 4 & 3,66 & 0,03 & 248 & 8,87 & 22 & 18,20 & 0,79 & 1439 & 8,86 & 128 & 130,00 & 0,03 \\
\hline IV & 107 & 7,48 & 8 & 8,89 & 0,09 & 119 & 16,81 & 20 & 8,74 & 14,50 & 584 & 15,51 & 85 & 52,70 & 19,80 \\
\hline v & 84 & 7,14 & 6 & 6,98 & 0,14 & 79 & 6,33 & 5 & 5,80 & 0,11 & 384 & 13,22 & 46 & 34,60 & 3,72 \\
\hline VI & 82 & 7,32 & 6 & 6,82 & 0,10 & 282 & 3,90 & 11 & 20,70 & 4,55 & 1031 & 6,60 & 68 & 93,00 & 6,73 \\
\hline Total & 409 & & & & 5,70 & 817 & & & & 23,41 & 3702 & & & & 42,46 \\
\hline
\end{tabular}

De acordo com BERNET et al. (1999), neoplasias são lesões especificas, comumente achadas em peixes de fundo de áreas poluídas, revelando uma associação entre as lesões e a exposição a irritantes. Rineloricaria strigilata é um peixe de fundo, que se alimenta no substrato, onde permanece constantemente apoiada, mesmo durante sua atividade de alimentação, o que corrobora a afirmação de BERNET et al. (1999). Durante o período de estudo, neoplasias a nível epidérmico foram observadas esporadicamente nos lambaris Astyanax bimaculatus (Linnaeus, 1758) (0,013\% da amostra) e Astyanax fasciatus (Cuvier, 1819) (0,010\%), no biru Cyphocharax voga (Hensel, 1870$)(0,029 \%)$, nos bagres Parapimelodus nigribarbis (Boulenger, 1889) (0,338\%) e Pimelodus maculatus Lacepède, $1803(0,025 \%)$, e em maior freqüência no cascudo-viola Loricariichthys anus (Valenciennes, 1840) $(1,414 \%)$. Somente nesta última espécie, também de fundo e que se alimenta no substrato, foi demonstrada a presença de freqüências acima do esperado de neoplasias a nível epidérmico no lago Guaíba comparativamente a amostras controle.

Mudanças patológicas são indicadoras de exposição a contaminantes, sendo a histologia uma ferramenta útil na avaliação de efeitos subletais e crônicos causados pela presença de poluentes. Mudanças histológicas aparecem como uma resposta intermediária para estressores subletais e a histologia provê um rápido método para detectar efeitos de irritantes em tecidos e órgãos (BERNET et al. 1999). Sinais de doença, como lesões epidérmicas, podem ser uma característica de peixes residentes em habitats degradados, onde o estresse ambiental foi provocado por compostos químicos tóxicos (SINDERMANN 1979). Segundo SHEPHARD (1994), o muco representa um importante papel na resistência contra agentes patogênicos e substâncias tóxicas, bem como uma série enorme de outras funções. A grande concentração de células mucosas que encontramos difundidas no tecido epitelial de $R$. strigilata indicam que, provavelmente, isso seja um mecanismo de defesa do peixe contra a ação de algum fator estressor do meio ambiente.

A ocorrência de neoplasias, com um padrão idêntico em placas ósseas de diversos indivíduos de $R$. strigilata, é uma evidência da presença de poluentes e/ou habitats degradados no lago Guaíba, e a análise da variação espacial e temporal de sua freqüência de ocorrência neste ambiente representa uma fonte importante de avaliação e monitoramento da qualidade da água deste manancial. 
Os resultados demonstraram nos três períodos amostrados uma freqüência mais elevada de neoplasias em $R$. strigilata no lago Guaiba $(8,31 \%, 7,34 \%$ e $9,02 \%)$ do que nas amostras comparativas de outros locais $(2,76 \%)$, evidenciando a maior presença de agentes estressores no lago Guaíba do que em outros locais. Nos três períodos estudados, observou-se também a repetição de um padrão de ocorrência destas neoplasias entre os locais amostrados no lago Guaíba, com o registro de freqüência igual a zero no ponto I e freqüências de indivíduos com neoplasias em placas ósseas variando de 3,04 a 16,81\% nos pontos II, III, IV, V e VI (Fig. 5).

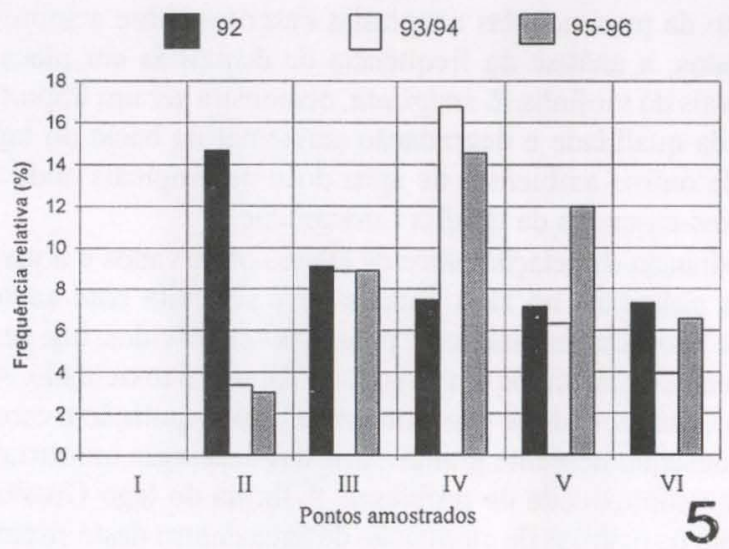

Fig. 5. Variação da freqüência relativa de neoplasias em placas ósseas em Rineloricaria strigilata entre os pontos de coleta em cada um dos três períodos amostrados.

As diferenças entre o aporte de água no ponto I (Saco da Alemoa) e os demais locais amostrados são consideráveis. A massa de água que banha o ponto I (Saco da Alemoa) provem do Canal Três Rios, que conecta-se ao rio Jacuí através do Canal do Lage e Canal Formoso. Já o ponto II (Ponta da Cadeia) e pontos III, IV, V e VI, a jusante, recebem, além da água do rio Jacuí, toda a contribuição do rio dos Sinos e rio Gravataí, através do Canal dos Navegantes, bem como a descarga do esgoto doméstico da grande Porto Alegre. Os rios Gravataí e Sinos, principalmente o primeiro, que drenam grande parte da região metropolitana e industrial de Porto Alegre e cidades circunvizinhas, e o esgoto doméstico da grande Porto Alegre podem estar relacionados à descarga de agentes estressores causadores de neoplasias em $R$. strigilata. A amostragem e monitoramento da ocorrência de neoplasias em placas ósseas da violinha, $R$. strigilata, ao longo dos rios Gravataí e Sinos podem servir como parâmetros importantes na detecção das fontes de eventuais poluentes.

A maior parte das publicações existentes acerca de anomalias causadas por substâncias tóxicas provêm de testes de laboratório, sendo os estudos de campo escassos. De acordo com BERGMAN (1985), isto se deve ao fato de peixes afetados por displasias apresentarem menores chances de sobrevivência, sendo eliminados da população antes de serem detectados. Esta baixa freqüência de detecção em campo deste tipo de efeito sobre populações naturais tornaria análises deste tipo 
impraticáveis. Segundo THOMAS (1990), estressores subletais provocam um complexo grupo de mudanças fisiológicas, comportamentais, imunológicas e patológicas em peixes, o que pode direcionar para prejuízo do crescimento, performance da natação, resistência a doenças e função reprodutiva. A análise periódica da freqüência de alterações morfológicas relacionadas a displasias dos ossos do crânio observadas em populações naturais do lambari Astyanax bimaculatus, no entanto, foi utilizada com resultados satisfatórios por MALABARBA \& GOETTEMS (1987) e por GOETTEMS et al. (1987) no monitoramento da eficiência de lagoas de estabilização terciárias no tratamento final de efluentes petroquímicos. Embora não seja possível avaliar o impacto da presença das neoplasias descritas sobre a sobrevivência dos indivíduos afetados, a análise da freqüência de displasias em placas ósseas em populações naturais da violinha $R$. strigilata, demonstra ser um importante fator de monitoramento da qualidade e degradação ambiental na bacia do lago Guaíba, e possivelmente de outros ambientes de água doce neotropicais onde se observe a presença de peixes-cascudos da família Loricariidae.

A determinação da relação entre os efeitos observados e a presença de um ou mais agentes poluentes no lago Guaíba deve ser feita com cautela devido à complexidade de fatores potencialmente poluidores envolvidos, que geralmente não são satisfatoriamente conhecidos em termos de volume e toxicidade. A localização da bacia do lago Guaíba, onde se concentram $70 \%$ da população e cerca de $80 \%$ do PIB gaúcho, e consequentemente grande parte das descargas industrial e urbana do estado, ilustra a complexidade do problema. A forma do lago Guaíba e a falta de informações sobre os padrões de circulação de água dentro deste sistema, impedem ainda, uma correlação precisa entre os resultados obtidos e fontes de descarga de rejeitos domésticos ou industriais. A verificação da existência de relação causal na literatura entre o tipo de deformação física observada e algum contaminante é dificultada, ainda, pela inexistência de descrições de efeitos observados sobre espécies de peixes nativas a partir de experimentos de laboratório. As análises realizadas permitem a verificação da freqüência de neoplasias ou displasias nas populações analisadas, indicando áreas ou períodos mais criticamente afetados, que devem servir de base para o monitoramento da qualidade ambiental.

AGRADECIMENTOS. Os autores são gratos ao Prof. Dr. João Carlos B. Cousin pela valiosa revisão crítica do artigo. As coletas foram realizadas com auxilio da RIOCELL.

\section{REFERÊNCIAS BIBLIOGRÁFICAS}

BERgMAN, H. 1985. Assessment protocols for the identification and quantification of injury to fishery resources. Washington, Progress Report, U.S. Dep. Interior, 98p.

Bernet, D.H.; W. Schmidt; P. MeIer; Burkhardt-Holm \& T. Wahl. 1999. Histopathology in fish: proposal for a protocol to assess aquatic pollution. Journ. Fish Diseases 22: 25-34.

Emater. 1991. Manejo dos Recursos Naturais Renováveis (área do Projeto 4): Pro-Guaíba. Porto Alegre, EMATER, Resumo Parcial, 14p.

EPA. 1984. Development of Water Quality-Based Permit Limitations for Toxic Pollutants: National Policy. Federal Register Notices, Washington, 49 (48): 9016-9019.

FEPAM. 1992. Rio Grande do Sul - 92. Perfil Ambiental e Estratégias. Porto Alegre, FEPAM/FAPERGS, 20p. 
GoEtTEMS, E.M.P.; R.L. TEixEIRA \& L.R. MALABARBA. 1987. Biological aspects in the evaluation of Tertiary lagoons and efficiency in the removal of organic pollutants. Water Sci. Technol. 19 (7): 1259-1261.

Gonzalez, G.; S. Crespo \& J. BRuSKE. 1993. Histo-cytological study of the liver of the cabrilla sea bass, Serranus cabrilla (Teleostei, Serranidae), an available model for marine fish experimental studies. Jour. Fish Biol. 43: 363-373

Malabarba, L.R. \& E.M.P. Goettems. 1987. Estudos sobre a ictiofauna das lagoas de Estabilização Terciárias do SITEL. An. 14 Congr. Brasil. Engenharia Sanit. Amb., São Paulo, p. 74-120.

Peltier, W. \& C.I. WeBer. 1985. Methods for measuring the acute toxicity of effluents to aquatic organisms. Cincinnati, U.S. Environ. Protection Agency, $3^{\text {rd }}$ ed., 217p.

SHEPHARD, K.L. 1994. Functions for fish mucus. Rev. Fish Biol. Fish. 4: 401-429.

SindERMANN, C.J. 1979. Pollution-associated diseases and abnormalities of Fish and Shellfish: a review. Fishery Bull., 76 (4): 717-749.

SNIESZKO, S.F. 1974. The effects of environmental stress on outbreaks of infectious diseases of fishes. Jour. Fish Biol. 6: 197-208.

Sprague, J.B. 1985. Factors that modify toxicity. In: Rand, G. M. \& S. R. Petrocelli. 1985. Fundamentals of Aquatic Toxicology: methods and applications. Washington, D.C., Hemisphere Publ. Co., XX+666p.

Thомлs, P. 1990. Molecular and biochemical responses of fish to stressors and their potential use in environmental monitoring. Amer. Fish. Soc. Symp. 8: 9-28.

Walters, G.R. \& J.A. Plumb. 1980 Environmental stress and bacterial infection in channel catfish, Ictalurus punctatus Rafinesque. Jour. Fish Biol. 17: 177-185.

Recebido em 11.V.2000; aceito em 16.VII.2001. 